Disponível em:

http://editora.unoesc.edu.br/index.php/race

RACE, Joaçaba, v. 17, n. 2, p. 732-756, maio/ago. 2018

\title{
INDICADORES DE DESEMPENHO COMO FERRAMENTA DE GESTÃO NO TERCEIRO SETOR: UM CASO PRÁTICO APLICADO A UM SINDICATO PATRONAL
}

Key performance indicators as a management tool in the third sector: a practical case applied to a trade union

Leonardo Fabris Lugoboni

E-mail: leo_fabris@hotmail.com

Doutor em Administração pela Universidade de São Paulo; Mestre em Administração pela Universidade Municipal de São Caetano do Sul; Professor no Centro Universitário FECAP; Professor no Insper Instituto de Ensino e Pesquisa.

Camilla Sampaio Custódio Cabral

E-mail: camilla.cabral@edu.fecap.br

Especialista em Controladoria pelo Centro Universitário FECAP; Graduada em Ciências Contábeis pelo Centro Universitário FIEO - UNIFIEO; Gerente Financeira e de controladoria no Sindicato das Empresas de Serviços Contábeis, Assessoramento, Perícias, Informações e Pesquisas no Estado de São Paulo (Sescon-SP).

Amanda Russo Chirotto

E-mail: amanda.chirotto@fecap.br

Mestre em Ciências Contábeis pelo Centro Universitário FECAP; Especialista em Gestão Empresarial pelo Centro Universitário Álvares Penteado; Professora no Centro Universitário FECAP.

Marcus Vinicius Moreira Zittei

E-mail: marcuszittei@zittei.com.br

Mestre em Ciências Contábeis pelo Centro Universitário FECAP; Doutor em Ciências Contábeis e Administração pela Fundação Universidade Regional de Blumenau; Professor no Mestrado do Centro Universitário das Faculdades Metropolitanas Unidas; Contador; Empresário contábil.

Endereço para contato: Rua Vergueiro, 107, Liberdade, 01504-001, São Paulo, São Paulo, Brasil.

Artigo recebido em 20 de agosto de 2017. Aceito em 05 de junho de 2018. 
Resumo

A utilização de ferramentas de monitoramento, controle e análise de desempenho estão cada vez mais evidentes e necessárias, principalmente ao analisar a situação do cenário econômico e competitivo em que as organizações estão se deparando. No terceiro setor o cenário não é diferente, ao mesmo passo que as organizações crescem, a competitividade e a necessidade de evolução são latentes. Nesse contexto, unindo a necessidade de criar ferramentas de controle e a complexidade do terceiro setor, nesta pesquisa teve-se como objetivo compreender quais indicadores de desempenho são utilizados por uma entidade sindical, e de que forma eles auxiliam na gestão dessas entidades. Para isso, foi realizada uma pesquisa exploratória, utilizando como procedimento entrevista com quatro gestores da entidade sindical. Os resultados evidenciaram que a avaliação de desempenho faz parte da cultura organizacional do sindicato, utilizando ferramentas como: planejamento estratégico, participação em programas de qualidade do segmento e indicadores de desempenho. Todos os departamentos pesquisados utilizam indicadores de desempenho, com medições distribuídas entre: semestrais e anuais, com divulgações que são realizadas por meio de relatórios e reuniões. A opinião dos entrevistados é uniforme ao considerar a relevância da utilização dos indicadores, assim como a aderência ao conceito de ferramenta de gestão para o terceiro setor.

Palavras-chave: Indicadores de desempenho. Sindicatos. Terceiro setor. Indicadores.

\section{Abstract}

The use of monitoring, control and performance analysis tools are becoming more evident and necessary, especially when analyzing the economic and competitive scenario that companies are facing. This scenario is no different in the third sector: while organizations grow, competitiveness and the need for evolution become latent. In this context, bringing together the need to create control tools and the complexity of the third sector, this research aims to understand which key performance indicators are used by a union, and how they assist in the management of these entities. To this end, exploratory research was carried out using interviews with four trade union managers. The results revealed that performance evaluation is part of the union's organizational culture, by using tools such as strategic planning, participation in the sector's quality programs, and key performance indicators. All the departments surveyed use key performance indicators, with semiannual and annual measurements, and disclosures that occur by means of reports and meetings. The opinion of the interviewees is always equal concerning the relevance of the use of indicators, as well as adherence to the concept of management tools for the third sector.

Keywords: Key performance indicators. Trade unions. Third sector. Indicators. 


\section{INTRODUÇÃO}

Com o cenário econômico cada vez mais competitivo, analisar o desempenho organizacional torna-se um fator indispensável às empresas (BONFIM; TEIXEIRA; CALLADO, 2013). As inovações tecnológicas estão exigindo que as organizações aprimorem o controle e o acompanhamento de seu desempenho (MUNARETTO; CORRÊA, 2016).

Do mesmo modo, Fischmann e Zilber (2000) relatam que é fundamental adotar técnicas de monitoria, as quais orientem a tomada de decisão, definindo os indicadores de desempenho como um instrumento capaz de auxiliar na definição do planejamento estratégico e na avaliação dos resultados alcançados.

Para justificar investimentos, os indicadores financeiros eram aceitos no passado, contudo, estratégias baseadas no conhecimento vêm ganhando força e angariando um papel substancial nas organizações (SOUZA; CORRÊA; 2014).

Para Marquezan, Diehl e Alberton (2013), os indicadores não financeiros atendem a diversos níveis nas organizações, pois são de fácil interpretação e oferecem grande possibilidade de mensurar as atividades durante sua execução.

As análises de desempenho bem como a adoção de boas práticas de governança são características intrínsecas de empresas com finalidade lucrativa, entretanto, pode-se verificar no terceiro setor a mesma necessidade, em vista da relação entre os gestores e os doadores. (ÁVILA; BERTERO, 2016). Caracterizadas como organizações de direito privado e finalidade pública, a análise de desempenho por parte dos stakeholders e a necessidade de prestação de contas são recorrentes (CRUZ et al., 2009).

Salamon (1998) afirma que o terceiro setor é composto por organizações absurdamente diversificadas, provocando sérios problemas de definição conceitual. Piza et al. (2012) completam que o terceiro setor é composto por entidades filantrópicas, sem fins lucrativos, de benemerência e sociais, que integram a sociedade civil, não visam lucros e não possuem vínculo governamental.

A necessidade de criar ferramentas de controle, atrelada à complexidade das entidades do terceiro setor apresentadas anteriormente remetem à importância do tema e justificam a necessidade de aprofundamento da discussão. Dados do Ministério do Trabalho, mais especificamente sobre as entidades sindicais, apontam a existência de aproximadamente 11 mil entidades sindicais cadastradas e habilitadas para o recebimento de contribuições no Brasil, delimitando o presente estudo às entidades (MINISTÉRIO DO TRABALHO E EMPREGO, 2013). 
Pesquisas em diversos segmentos abordam a utilização de indicadores de desempenho em cooperativas de eletrificação (MUNARETTO; CORRÊA, 2016), shopping centers (LUGOBONI et al. 2014), hospitais (VIGNOCHI; GONÇALO; LEZANA, 2014), instituições de ciência, tecnologia e inovação (FRARE et al., 2014) e micro e pequenas empresas BONFIM; TEIXEIRA; CALLADO, 2013); entretanto, não foi possível localizar nenhuma que relate a utilização de indicadores de desempenho em entidades sindicais, legitimando a realização do presente estudo.

Dentro desse contexto, nesta pesquisa teve-se como objetivo compreender quais indicadores de desempenho são utilizados por uma entidade sindical e de que forma eles auxiliam na gestão dessa entidade.

\section{REFERENCIAL TEÓRICO}

\subsection{AVALIAÇÃO DE DESEMPENHO NO TERCEIRO SETOR}

A competitividade do mercado tem feito com que os gestores busquem um resultado cada vez maior e positivo para as organizações, nessa perspectiva, métodos de avaliação e gerenciamento de desempenho vêm ganhando espaço (GARCIA et al., 2013).

Nesse sentido, Klann e Beuren (2011) destacam que a apresentação de informações voluntárias vem crescendo, fazendo com que as organizações adotem uma postura de maior transparência, trazendo evidências e avaliações complementares, além das exigidas legalmente.

Já para Souza e Corrêa (2014), a avaliação do desempenho adquire um papel fundamental nas organizações, fornecendo dados fundamentais para o adequado gerenciamento de suas atividades.

Dutra (2005) indica que avaliar significa conferir valor ao que a organização considera importante, estabelecendo relação com seu objetivo estratégico e possibilitando observar em que ponto está e quais ações de melhoria precisa tomar. Para Valente (2014) é primordial que as avaliações de desempenho estejam alinhadas com a razão de existência da organização, assegurando que sua missão institucional seja cumprida. Esse alinhamento permitirá mensurações sobre controle e até se os dispêndios de recursos estão sendo aplicados de maneira adequada na missão organizacional.

Garcia et al. (2013) argumentam que apesar da importância da avaliação de desempenho é necessário reconhecer que o conjunto de indicadores deve estar alinha- 
do com os objetivos da organização. Para Nascimento et al. (2011) a avaliação deve ter a intervenção dos objetivos e metas da organização e estes devem estar relacionados às fases de execução e planejamento das ações.

A análise de desempenho de uma organização, para Macedo, Barbosa e Cavalcante (2009), é propensa a muitas discussões e questionamentos sobre o justo critério de avaliação da performance, no entanto, destacam que não existe um modelo específico que se encaixe em qualquer tipo de organização, pois são inúmeras as variáveis do mundo empresarial.

Callado et at. (2012) ressaltam que a definição do que deve ser avaliado não é tarefa fácil, entretanto, depende da complexidade do que se pretende avaliar, da sua importância em relação às metas da organização, da integração com suas diversas áreas, além da perspectiva do uso gerencial das informações avaliadas. A gestão estratégica dessas informações, nortearão a tomada de decisão, direcionarão mudanças e aperfeiçoarão as previsões sobre o futuro.

Rezende, Dieng e Moraes Júnior (2011) afirmam que para medir o desempenho das organizações é necessário que os gestores procurem aperfeiçoar as metas empresariais alcançando os resultados desejados. É dessa maneira que as organizações se baseavam em relatórios financeiros, fornecidos pela contabilidade para avaliar o desempenho organizacional.

Nesse ínterim, Souza e Corrêa (2014) destacam que os indicadores financeiros eram bem-aceitos no passado, assim como Marquezan, Diehl e Alberton (2013) enfatizam que os indicadores financeiros atendem a níveis específicos dentro da organização, pois não são de fácil interpretação. Acrescentam, ainda, que a avaliação de desempenho não financeira possibilita mensurar as atividades durante sua execução por unidades de medidas de fácil interpretação pelos diversos níveis da empresa.

Kaplan e Norton (1992) já destacavam que os indicadores individualmente não são capazes de evidenciar a performance da organização. Nessa mesma linha Callado, Callado e Almeida (2008b) afirmaram que é importante observar o ângulo gerencial que está por trás da implantação e do monitoramento dos indicadores de desempenho, de modo que eles sejam referência estratégica e decisória de uma organização.

Em uma visão mais técnica, Kueng, Meier e Wettstein (2000) classificam como Sistema de Medição de Desempenho (SMD) e definem como um sistema de informação e coleta de dados, com a finalidade de analisar, comparar as informações e disponibilizá-las aos usuários. A medição, financeira ou não, trata-se de uma operação estratégica com a finalidade de gerar informações para a gestão, e, por meio dela, relatórios e indicadores que demonstrarão a sua posição perante o mercado e suprirão 
as necessidades de informações advindas dos stakeholders (CALLADO; CALLADO; ALMEIDA, 2008a).

No mesmo sentido técnico, Figueiredo et al. (2005) destacam que o sistema de medição de desempenho deve possibilitar analisar se as decisões tomadas estão fluindo de acordo com o planejado. Afirmam, ainda, que a medição não deve ser de responsabilidade exclusiva da direção e deve ser compartilhada com os gerentes, supervisores e colaboradores de todos os níveis da organização, envolvendo-os de forma ativa, e também, do mesmo modo, na implementação e no aperfeiçoamento do sistema de gestão do desempenho.

Não somente as empresas do segmento privado passam por mudanças, mas também as organizações do terceiro setor, principalmente quando o assunto está relacionado a ferramentas de medição de desempenho, uma vez que a maior preocupação desse setor é a prestação de contas não apenas ao Governo, mas também à sociedade e às entidades que as financiam (ESTENDER; FREITAS; CARVALHO, 2007).

Tradicionalmente, a avaliação do desempenho é aplicada com o objetivo de maximizar os lucros. Transportando para a natureza do terceiro setor, entidades que em sua maioria são dirigidas por abnegados, em que a experiência administrativa não é característica compulsória, é cada vez mais percebida a necessidade de uma gestão profissional (ENSSLIN; VIANNA, 2007). Para Cairns et al. (2005), o terceiro setor é permeado por expectativas, e as pressões para a melhoria do desempenho advêm de diversas fontes, como beneficiários, doadores e as próprias organizações que lutam para prestar bons serviços e mostrar que trabalham de forma eficaz e sem desperdício de recursos. Nesse mesmo contexto, Barney (1991) destaca a complexidade em mensurar o desempenho nessas organizações ao considerar o ponto de vista dos stakeholders.

Kaplan (2001) aponta que o sucesso dessas organizações deve ser medido de forma eficiente de modo a satisfazer às necessidades dos stakeholders. Destaca, também, a importância da avaliação financeira, embora esta dificilmente seja um fator primordial, pois a satisfação no terceiro setor está ligada à missão e aos objetivos dessas organizações.

No mesmo sentido, Souza e Souza (2011) apresentam a dificuldade histórica que o terceiro setor enfrenta quando o assunto é construção de indicadores, visto que o lucro financeiro não pode ser utilizado como principal medida. Reforçam que essas organizações atuam como agentes de mudanças nas pessoas, os seus resultados estão relacionados a mudanças em comportamentos, condições, conhecimentos e competências, e esses resultados determinarão a capacidade de desempenho da organização. 


\subsection{INDICADORES DE DESEMPENHO}

Os indicadores são elementos fundamentais para a mensuração da performance das empresas (CALLADO; CALLADO; ALMEIDA, 2008a) bem como para avaliar o cumprimento dos objetivos e o seu desempenho (FERREIRA; OTLEY, 2009).

Marquezan, Diehl e Alberton (2013) definem os indicadores como processos de mensuração e controle que identificam os pontos fortes e as necessidades de melhorias e mudanças, buscando sempre atingir objetivos previamente definidos. Destaca-se a sua classificação mais comum entre: financeiros (expressos em moeda) e não financeiros (expressos em unidades de medidas, qualitativas ou quantitativas).

Para Souza e Corrêa (2014), os indicadores precisam contemplar dados financeiros, não financeiros, internos, externos, quantitativos, qualitativos, de curto e de longo prazo. Destacam, ainda, a necessidade de estabelecer indicadores relacionados à prática de gestão de pessoas, estimulando a participação e a satisfação dos empregados.

Callado, Callado e Almeida (2008a) observam que a tomada de decisão exige a análise de um vasto número de variáveis, como: satisfação dos clientes, qualidade dos produtos, participação no mercado, fidelidade dos clientes, inovação, habilidades estratégicas, entre outras. Entretanto, contrapõem que os dados financeiros não devem ser negligenciados, pois são provas concretas do resultado das ações já tomadas.

Bortoluzzi et al. (2011), em seu estudo sobre indicadores contábeis tradicionais, apresentando as demonstrações contábeis e índices como liquidez, rentabilidade e estrutura de capitais como indicadores de desempenho financeiros destacam que mesmo não levando em consideração aspectos não financeiros em seu estudo, há muito espaço para a expansão e melhoria da informação, justificado pela profissionalização da gestão das organizações, que tem exigido cada vez mais modelos de gestão que gerem informações úteis.

Para Rezende, Dieng e Moraes Júnior (2011), as organizações precisam analisar os dados da contabilidade financeira e da gerencial para medir o seu desempenho.

O estabelecimento de indicadores deve fazer parte de uma sequência lógica de procedimentos voltados para o futuro, com o objetivo de revelar as metas da organização. Esses indicadores podem ser estabelecidos em cada setor de atividade (CALLADO; CALLADO; ALMEIDA; 2011). 


\subsection{PRERROGATIVAS DO TERCEIRO SETOR E ENTIDADES SINDICAIS}

A sociedade busca continuamente por lucros e se divide em dois segmentos: o público e o privado. O público, representado pelo Governo com o objetivo de promover a evolução da sociedade, e o privado, representado pela iniciativa privada, “o mercado”. Um terceiro segmento surge para complementar os outros dois já apresentados e sua principal finalidade é suprir as necessidades não atendidas pelos dois primeiros setores (ESTENDER; FREITAS; CARVALHO, 2007).

O terceiro setor é composto por organizações que não visam lucros e possuem objetivo social definido; a principal finalidade delas é gerar benefícios à sociedade e dependem de recursos provenientes de doações e trabalho voluntário (ASSAF NETO; ARAÚJO; FREGONESI; 2006).

Para Lugoboni et al. (2014), o terceiro setor é constituído por entidades da sociedade civil de interesse público, as quais têm a missão de atender às necessidades sociais coletivas, principalmente a faixa menos favorecida. Os autores esclarecem que essas entidades atuam com recursos de terceiros e que precisam demonstrar transparência aos stakeholders, bem como o destino dado os recursos recebidos. Destacam, ainda, os principais nomes dados às entidades do terceiro setor, como: Organização da Sociedade Cível e Interesse Público (OSCIP), Associações, Organizações Não Governamentais (ONGs), Organizações Filantrópicas, entre outros.

Marques et al. (2015) apontam que, no Brasil, o crescimento do terceiro setor é expressivo em razão de sua importância social, principalmente por suprir os hiatos deixados pelo Estado. Salamon (1998) indica que o terceiro setor cresce em decorrência da procura e das necessidades dos cidadãos e instituições, principalmente pela insegurança que possuem na capacidade do Governo em suprir suas necessidades. Destacam também que em decorrência dessas necessidades surgem entidades extremamente diversificadas, dificultando a exata compreensão sobre o papel que desempenham, qual terminologia carregam e qual tratamento jurídico recebem.

Dados publicados pelo IBGE (2010) ratificam um expressivo crescimento do setor até 2005 e certa estabilidade entre 2006 e 2010, conforme a Tabela 1: 
Tabela 1 - Crescimento do terceiro setor

Faixas de ano de fundação

Fundações privadas e associações sem fins lucrativos

\begin{tabular}{lrr} 
& Total & Percentual (\%) \\
\hline Total & 290.692 & 100 \\
Até 1970 & 9.558 & 3,3 \\
De 1971 a 1980 & 27.270 & 9,4 \\
De 1981 a 1990 & 45.132 & 15,5 \\
De 1991 a 2000 & 90.079 & 31 \\
De 2001 a 2005 & 58.388 & 20,1 \\
2006 & 11.869 & 4,1 \\
2007 & 11.551 & 4 \\
2008 & 11.464 & 3,9 \\
2009 & 13.726 & 4,7 \\
2010 & 11.655 & 4 \\
\hline Fonte: IBGE (2010). & &
\end{tabular}

Outro fator divulgado pelo IBGE (2010) e que corrobora os estudos e afirmações sobre o setor é que, em 2010, essas entidades representavam 5,2\% do total de entidades públicas e privadas existentes no Brasil e empregavam 4,9\% dos trabalhadores do Brasil, representando um contingente de 2,1 milhões de pessoas, ganhando em média R\$1.667,00, equivalente a 3,2 salários mínimos, em 2010.

A constituição de sindicatos é disciplinada por leis e está prevista na Constituição Federal e na Consolidação das Leis do Trabalho (CLT). A CLT, em seu artigo 513, estabelece as prerrogativas das entidades sindicais:

a) representar, perante as autoridades administrativas e judiciárias, os interesses gerais da respectiva categoria ou profissão liberal ou os interesses individuais dos associados relativos à atividade ou profissão exercida;

b) celebrar contratos coletivos de trabalho;

c) eleger ou designar os representantes da respectiva categoria ou profissão liberal;

d) colaborar com o Estado, como órgãos técnicos e consultivos, no estudo e na solução dos problemas que se relacionam com a respectiva categoria ou profissão liberal;

e) impor contribuições a todos aqueles que participam das categorias econômicas ou profissionais ou das profissões liberais representadas. (BRASIL, 1943). 
Já o artigo 514 da CLT estabelece os deveres:

a) colaborar com os poderes públicos no desenvolvimento da solidariedade social;

b) manter serviços de assistência judiciária para os associados;

c) promover a conciliação nos dissídios de trabalho.

d) sempre que possível, e de acordo com as suas possibilidades, manter no seu quadro de pessoal, em convênio com entidades assistenciais ou por conta própria, um assistente social com as atribuições específicas de promover a cooperação operacional na empresa e a integração profissional na Classe. (BRASIL, 1943).

O órgão competente para fornecer o registro sindical é o Ministério do Trabalho e Emprego (MTE). De acordo com dados do próprio MTE, existem aproximadamente 11 mil entidades sindicais cadastradas e habilitadas para o recebimento de contribuições no Brasil, com uma arrecadação, somente de janeiro a maio de 2016, de aproximadamente 3,4 bilhões (MINISTÉRIO DO TRABALHO E EMPREGO, 2013).

Esses dados somente puderam ser identificados em razão de uma determinação recente da Controladoria Geral da União (CGU), designando ao Ministério do Trabalho e Emprego (MTE) disponibilizar as informações a todos os cidadãos. A CGU utilizou a Lei de Acesso à Informação (LAI) (Lei n. 12.527/2011), que regulamenta o direito de acesso às informações públicas, inclusive para entidades sem fins lucrativos, que são obrigadas a dar publicidade a informações referentes ao recebimento e à destinação dos recursos públicos por elas recebidos.

Essas características reafirmam os destaques de Carlos et al. (2008) sobre o conceito de accountability no setor público, objetivando demonstrar a aplicabilidade dos recursos, e de Lugoboni et al. (2014) sobre a necessidade do terceiro setor em certificar transparência (accountability) aos stakeholders.

\subsection{ESTUDOS CORRELATOS}

Souza e Souza (2011), com o objetivo de analisar modelos de desempenho voltados para entidades do terceiro setor, realizaram um estudo resgatando metodologias e propondo um modelo de indicadores adaptado, em decorrência da especificidade e diversidade das áreas de atuação e dos beneficiários, concluindo que a aplicação 
desse modelo permitirá a análise de desempenho, respeitando as particularidades de cada organização, além de possibilitar a comparação entre si.

Lugoboni et al. (2014), compreendendo a representatividade e a importância do terceiro setor e da avaliação de desempenho organizacional, realizaram um levantamento bibliográfico e concluíram que, dos diversos métodos de avaliação de desempenho pesquisados, nenhum deles, isoladamente, é capaz de suprir e mensurar todas as variáveis requeridas pelo setor.

Marques et al. (2015), avaliando a relevância e o crescimento do terceiro setor, realizaram um estudo bibliométrico mapeando os artigos publicados em congressos e periódicos nacionais sobre o tema, identificando uma média de sete trabalhos publicados entre 1998 e 2003, contribuindo para a criação de um panorama da criação científica sobre o terceiro setor.

\section{METODOLOGIA}

A pesquisa caracteriza-se como exploratória, pois tem como objetivo analisar a utilização de indicadores de desempenho e a aplicabilidade no processo de gestão de um sindicato patronal localizado no Estado de São Paulo. De acordo com Gil (2002), o objetivo das pesquisas exploratórias é permitir maior proximidade com o tema de modo a refinar ideias e evidenciar impressões.

Quanto aos procedimentos, foram realizadas entrevistas com os gestores ou responsáveis pelos indicadores de desempenho da entidade. Para possibilitar a tabulação e a comparabilidade, as entrevistas foram realizadas por meio de um roteiro previamente estabelecido.

Esse roteiro foi composto por três etapas: a definição do perfil dos entrevistados, informações relacionadas ao departamento e um questionário com assuntos relacionados: à avaliação do desempenho (KUENG; MEIER; WETTSTEIN, 2000), à aplicabilidade dos indicadores de desempenho (FISCHMANN; ZILBER, 2000), ao alinhamento estratégico (SOUZA; CORRÊA; 2014; DUTRA, 2005; FIGUEIREDO et al., 2005), à medição dos indicadores (CALLADO et al., 2012; FIGUEIREDO et al., 2005) e à avaliação de desempenho no terceiro setor (LUGOBONI et al., 2014). 
Leonardo Fabris Lugoboni et al.

Quadro 1 - Roteiro de entrevista

\begin{tabular}{|c|c|c|c|}
\hline Assunto & Subassunto & Autor & Pergunta \\
\hline \multirow{5}{*}{$\begin{array}{l}\text { Avaliação } \\
\text { do desempe- } \\
\text { nho }\end{array}$} & \multirow{2}{*}{$\begin{array}{l}\text { Formas de } \\
\text { avaliação }\end{array}$} & \multirow{2}{*}{$\begin{array}{l}\text { Kueng, Meier e } \\
\text { Wettstein (2000) }\end{array}$} & $\begin{array}{l}\text { Sua organização possui métodos de avaliação } \\
\text { de desempenho? }\end{array}$ \\
\hline & & & De que forma a avaliação é realizada? \\
\hline & \multirow{3}{*}{$\begin{array}{l}\text { Alinhamento } \\
\text { estratégico }\end{array}$} & \multirow{2}{*}{ Valente (2014) } & $\begin{array}{l}\text { Como a organização divulga essas informa- } \\
\text { ções? }\end{array}$ \\
\hline & & & Qual a frequência da avaliação dos resultados? \\
\hline & & $\begin{array}{l}\text { Souza e Corrêa } \\
\text { (2014)/Dutra (2005) }\end{array}$ & $\begin{array}{l}\text { Você considera que esse tipo de avaliação é } \\
\text { importante para a organização? }\end{array}$ \\
\hline \multirow{7}{*}{$\begin{array}{l}\text { Indicadores } \\
\text { de desempe- } \\
\text { nho }\end{array}$} & \multirow[b]{2}{*}{$\begin{array}{l}\text { Aplicabilidade } \\
\text { dos indica- } \\
\text { dores }\end{array}$} & $\begin{array}{l}\text { Fischmann e Zilber } \\
(2000)\end{array}$ & $\begin{array}{l}\text { Ao avaliar o desempenho, sua organização } \\
\text { utiliza indicadores? }\end{array}$ \\
\hline & & $\begin{array}{l}\text { Garcia et al. (2013) } \\
\text { e Valente (2014) }\end{array}$ & $\begin{array}{l}\text { Ao determinar os indicadores de desempenho } \\
\text { de seu departamento, há alguma relação, ou } \\
\text { ainda, alguma preocupação com os objetivos e } \\
\text { metas da organização? Poderia explicar? }\end{array}$ \\
\hline & $\begin{array}{l}\text { Relação com o } \\
\text { planejamento } \\
\text { estratégico }\end{array}$ & $\begin{array}{l}\text { Nascimento et al. } \\
\text { (2011) }\end{array}$ & $\begin{array}{l}\text { Há relação entre os indicadores e o plane- } \\
\text { jamento estratégico? Em que momento é } \\
\text { realizado? }\end{array}$ \\
\hline & \multirow{2}{*}{$\begin{array}{l}\text { Informações } \\
\text { financeiras e } \\
\text { não financeiras }\end{array}$} & $\begin{array}{l}\text { Souza e Corrêa } \\
\text { (2014) }\end{array}$ & $\begin{array}{l}\text { Os dados monitorados contemplam informa- } \\
\text { ções financeiras e não financeiras? }\end{array}$ \\
\hline & & $\begin{array}{l}\text { Kaplan e Norton } \\
\text { (1992) }\end{array}$ & $\begin{array}{l}\text { Quantos indicadores de desempenho o seu } \\
\text { departamento possui? Dividir entre financeiros } \\
\text { e não financeiros? }\end{array}$ \\
\hline & \multirow{2}{*}{$\begin{array}{l}\text { Medição dos } \\
\text { indicadores }\end{array}$} & $\begin{array}{l}\text { Figueiredo et al. } \\
\text { (2005) }\end{array}$ & $\begin{array}{l}\text { Como é realizada a medição dos indicadores? } \\
\text { Qual o nível hierárquico dos envolvidos na } \\
\text { medição? }\end{array}$ \\
\hline & & Callado et al. (2012) & $\begin{array}{l}\text { Já tomou alguma decisão importante em seu } \\
\text { departamento, baseada nos indicadores? Cite } \\
\text { exemplos. }\end{array}$ \\
\hline \multirow{4}{*}{$\begin{array}{l}\text { Avaliação } \\
\text { de desem- } \\
\text { penho no } \\
\text { terceiro } \\
\text { setor }\end{array}$} & \multirow{3}{*}{$\begin{array}{l}\text { Formas de } \\
\text { avaliação }\end{array}$} & $\begin{array}{l}\text { Lugoboni et al. } \\
\text { (2014) }\end{array}$ & $\begin{array}{l}\text { Você acredita que os indicadores de desem- } \\
\text { penho são importantes para as organizações } \\
\text { desse segmento? }\end{array}$ \\
\hline & & \multirow{2}{*}{$\begin{array}{l}\text { Carlos et al. (2008) } \\
\text { e Lugoboni et al. } \\
\text { (2014) }\end{array}$} & $\begin{array}{l}\text { Há diferenças ao compará-los com organiza- } \\
\text { ções de outros segmentos? Explique. }\end{array}$ \\
\hline & & & $\begin{array}{l}\text { Você conhece organizações do mesmo seg- } \\
\text { mento que o SESCON-SP que utilizam indica- } \\
\text { dores de desempenho? }\end{array}$ \\
\hline & $\begin{array}{l}\text { Alinhamento } \\
\text { estratégico }\end{array}$ & $\begin{array}{l}\text { Figueiredo et al. } \\
\text { (2005) }\end{array}$ & $\begin{array}{l}\text { Qual a relação (preocupação) dos dirigentes/ } \\
\text { diretores e com os indicadores? Eles interfe- } \\
\text { rem na criação? Na avaliação dos resultados? }\end{array}$ \\
\hline
\end{tabular}

Fonte: os autores. 
As entrevistas foram realizadas presencialmente nos dias 11, 21 e 23 de novembro de 2016 na entidade sindical. A amostra desta pesquisa foi composta por 4 gestores de um mesmo sindicato patronal situado no estado de São Paulo, com 67 anos de existência e 235 colaboradores. Com a finalidade de não expor os dados dos respondentes e da organização, eles serão classificados pelos respectivos departamentos, sendo: Relacionamento, Tecnologia da Informação, Conteúdo e Qualidade, conforme a Tabela 2:

Tabela 2 - Característica dos entrevistados

\begin{tabular}{llrr}
\hline \multicolumn{1}{c}{ Departamento } & Cargo & $\begin{array}{c}\text { Quantidade } \\
\text { colaboradores }\end{array}$ & $\begin{array}{c}\text { Quantidade } \\
\text { de indicadores } \\
\text { utilizados }\end{array}$ \\
\hline Relacionamento & Supervisor & 20 & 12 \\
$\begin{array}{l}\text { Tecnologia da Infor- } \\
\text { mação }\end{array}$ & Supervisor & 7 & 6 \\
Conteúdo & Supervisor & 8 & 6 \\
Qualidade & Supervisor & 3 & 7 \\
\hline Fonte: os autores. & & &
\end{tabular}

\section{ANÁLISE DOS RESULTADOS}

\subsection{APLICABILIDADE E MEDIÇÃO DOS INDICADORES DE DESEMPENHO}

Todos os departamentos indicaram que o sindicato realiza avaliação de desempenho por meio de indicadores. O Departamento da Qualidade indicou mais duas práticas adotadas pelo sindicato, além dos indicadores já citados: a realização de um planejamento estratégico anual e a participação no Sistema de Excelência em Gestão Sindical (SEGS), idealizado pela Confederação Nacional do Comércio (CNC), acompanhando Fischmann e Zilber (2000) ao relatarem que é fundamental adotar técnicas de monitoria definindo indicadores de desempenho capazes de auxiliar na definição do planejamento estratégico e na avaliação dos resultados alcançados.

Em relação à medição e à divulgação dos indicadores de desempenho dos departamentos foi possível evidenciar certa uniformidade nas repostas, cuja medição foi destacada com avaliação mensal dos departamentos e a divulgação dos dados, realizada por meio de reuniões e relatórios internos. Os Departamentos de Conteúdo e Qualidade destacaram a divulgação de alguns indicadores no Balanço Social apre- 
sentado anualmente pelo sindicato. Na visão do supervisor da área de Conteúdo “O Balanço Social é uma ferramenta importante, pois é o momento em que o sindicato presta conta aos associados e representados das diversas atividades realizadas ao longo do ano.” (informação verbal).

Ao serem questionados sobre a aplicabilidade e a importância da avaliação do desempenho, novamente se evidenciou certa uniformidade entre os departamentos pesquisados, o que se demonstra no Quadro 2:

Quadro 2 - Aplicabilidade e importância da avaliação de desempenho

\begin{tabular}{|l|l|}
\hline Departamento & $\begin{array}{l}\text { Você considera que a avaliação de desempenho é importante para a sua organi- } \\
\text { zação? }\end{array}$ \\
\hline Relacionamento & $\begin{array}{l}\text { Considero de extrema importância, pois norteiam os esforços para atingir de- } \\
\text { terminados objetivos. Conseguimos mensurar os resultados e propor estratégias } \\
\text { para a melhoria contínua. }\end{array}$ \\
\hline $\begin{array}{l}\text { Tecnologia da Infor- } \\
\text { mação }\end{array}$ & Sim, pois norteia os líderes e os colaboradores. \\
\hline Conteúdo & $\begin{array}{l}\text { Fundamental, pois oferecem subsídios para tomadas de decisões mais asserti- } \\
\text { vas. }\end{array}$ \\
\hline Qualidade & $\begin{array}{l}\text { Sim, pois a mesma demonstra a capacidade de cada processo cumprir os resul- } \\
\text { tados planejados. (informações verbais). }\end{array}$ \\
\hline
\end{tabular}

Fonte: os autores.

\subsection{ALINHAMENTO ESTRATÉGICO}

Outro quesito analisado nesta pesquisa exploratória é o alinhamento estratégico dos indicadores, direcionados por Garcia et al. (2013) e Nascimento et al. (2011) sobre a importância do alinhamento entre os indicadores e os objetivos, e o planejamento da organização.

Os entrevistados dos Departamentos de Relacionamento, Conteúdo e Qualidade fizeram referência ao planejamento estratégico, realizado anualmente pelo sindicato, e destacaram que os indicadores de desempenho são definidos durante a realização do planejamento estratégico, possibilitando, assim, o levantamento de cenários e estabelecimento de metas.

O Departamento de Tecnologia da Informação não mencionou o planejamento estratégico do sindicato e, ao ser questionado, informou que o planejamento estratégico não é aplicado a todos os departamentos de maneira similar, destacando que os indicadores da unidade são criados no mesmo período, entretanto, levam-se em consideração os objetivos e os valores da entidade como um todo. O Departamento 
da Qualidade também fez referência aos objetivos da entidade, indicando: “Alguns indicadores advêm do planejamento estratégico, outros de monitoramento em consonância com os objetivos da entidade.” (informação verbal).

O relato da área da qualidade condiz com as afirmações de Valente (2014) acerca do alinhamento dos indicadores de desempenho com a missão institucional.

O Departamento de Relacionamento destacou ainda um alinhamento estratégico relacionado ao orçamento anual do sindicato, permeando Souza e Corrêa (2014) sobre a necessidade de os indicadores contemplarem dados financeiros e não financeiros. Os entrevistados apresentaram o seguinte comportamento sobre a quantidade de indicadores utilizados e a divisão entre indicadores financeiros e não financeiros:

Tabela 3 - Indicadores financeiros e não financeiros

\begin{tabular}{lccc}
\hline \multicolumn{4}{c}{ Divisão entre indicadores financeiros e não financeiros } \\
\hline \multicolumn{1}{c}{ Departamento } & $\begin{array}{c}\text { Indicadores } \\
\text { financeiros }\end{array}$ & $\begin{array}{c}\text { Indicadores não } \\
\text { financeiros }\end{array}$ & $\begin{array}{c}\text { Quantidade total } \\
\text { de indicadores } \\
\text { utilizados }\end{array}$ \\
\hline $\begin{array}{l}\text { Relacionamento } \\
\text { Tecnologia da Infor- }\end{array}$ & 5 & 7 & 12 \\
mação & 0 & 6 & 6 \\
$\begin{array}{l}\text { Conteúdo } \\
\text { Qualidade }\end{array}$ & 0 & 6 & 6 \\
Fonte: os autores. & 0 & 7 & 7 \\
\hline
\end{tabular}

A Tabela 3 possibilita evidenciar que a menção ao orçamento, feita pelo Departamento de Relacionamento, está relacionada aos indicadores financeiros, suprimindo os demais departamentos pesquisados por não possuírem orçamento e indicadores financeiros específicos, em consenso com Marquezan, Diehl e Alberton (2013), que enfatizam que os indicadores financeiros atendem a níveis específicos dentro da organização.

Na visão do Departamento de Relacionamento: “Os indicadores não financeiros também são importantes, pois auxiliam a identificar a saúde financeira da entidade, além de possibilitar propor ações para redução de custos e aumentos de receitas.” (informação verbal).

\subsection{INDICADORES UTILIZADOS PELAS ÁREAS ENTREVISTADAS}

Observando Souza e Corrêa (2014), no sentido de que os indicadores precisam contemplar dados financeiros, não financeiros, internos, externos, quantitativos e 
qualitativos foram realizadas a análise e a relação no Quadro 3 dos indicadores utilizados pelos departamentos entrevistados:

Quadro 3 - Indicadores por departamento

\begin{tabular}{|c|c|c|}
\hline $\begin{array}{c}\text { De- } \\
\text { parta- } \\
\text { mento }\end{array}$ & Indicador & Medição \\
\hline \multirow{12}{*}{$\begin{array}{l}\text { Rela- } \\
\text { ciona- } \\
\text { mento }\end{array}$} & Atualização do banco de dados & Anual com demonstrativo mensal \\
\hline & Representatividade no Estado de São Paulo & $\begin{array}{l}\text { Número acumulado de filiados no } \\
\text { Estado de São Paulo }\end{array}$ \\
\hline & Aumento de Arrecadação - Contribuição Sindical & Anual \\
\hline & Aumento de Arrecadação - Contribuição Confederativa & Anual \\
\hline & Aumento de Arrecadação - Contribuição Assistencial & Anual \\
\hline & Aumento de Arrecadação - Contribuição Associativa & Anual \\
\hline & Redução da evasão de associados & Anual com demonstrativo mensal \\
\hline & Aumento do quadro associativo & Anual com demonstrativo mensal \\
\hline & Aumento de associados no interior & Anual com demonstrativo mensal \\
\hline & Aumento de organizações participantes no PQEC & Anual \\
\hline & Ampliação da Pesquisa de Satisfação & Anual \\
\hline & Satisfação do Associado & Anual \\
\hline \multirow{6}{*}{$\begin{array}{l}\text { Tecno- } \\
\text { logia } \\
\text { da } \\
\text { Infor- } \\
\text { mação }\end{array}$} & Atendimento dos Chamados & Mensal \\
\hline & Quantidade de Chamados (por tipo de atendimento) & Mensal \\
\hline & Quantidade de Chamados Reincidentes & Mensal \\
\hline & Quantidade de Chamados por Departamento & Anual \\
\hline & Quantidade de chamados por Serviço & Mensal \\
\hline & Quantidade de Chamados por Departamento & Mensal \\
\hline \multirow{6}{*}{$\begin{array}{l}\text { Con- } \\
\text { teúdo }\end{array}$} & Aumento de Inserções em Mídia Espontânea & Anual com demonstrativo mensal \\
\hline & Visualização de Vídeos no Canal do YouTube & Mensal \\
\hline & Visualização de Postagens na Rede Social & Mensal \\
\hline & Diminuição do número de informativos enviados & Anual \\
\hline & Conteúdo em Redes Sociais & Mensal \\
\hline & Venda de Anúncios na Revista & Anual \\
\hline
\end{tabular}




\begin{tabular}{|l|l|l|}
\hline $\begin{array}{c}\text { De- } \\
\text { parta- } \\
\text { mento }\end{array}$ & \multicolumn{1}{|c|}{ Indicador } & \multicolumn{1}{c|}{ Medição } \\
\hline \multirow{4}{*}{$\begin{array}{l}\text { Quali- } \\
\text { dade }\end{array}$} & Emissão das ações corretivas, preventivas e de melhoria & Anual \\
\cline { 2 - 4 } & Status das ações corretivas, preventivas e de melhoria & Anual \\
\cline { 2 - 4 } & Origem das ações corretivas, preventivas e de melhoria & Anual \\
\cline { 2 - 4 } & Revisão dos documentos do Sistema de Gestão da Qualidade & Anual \\
\cline { 2 - 4 } & Conformidade de Auditoria Interna por área & Semestral \\
\cline { 2 - 4 } & Conformidade da Gestão & Anual \\
\cline { 2 - 4 } & Diagnóstico da Gestão - SEGS & Anual \\
\hline
\end{tabular}

Fonte: os autores.

\subsection{UTILIZAÇÃO DOS INDICADORES COMO FERRAMENTA DE GESTÃO}

Os departamentos entrevistados mencionaram os indicadores para o atingimento de metas e objetivos de seus departamentos e do sindicato como um todo, demonstrando boa percepção e aderência ao conceito de ferramenta de gestão.

Ao comparar com outros segmentos e questioná-los sobre a aplicabilidade especificamente no terceiro setor, as respostas foram unânimes no sentido de evidenciar que são ferramentas poderosas. Na visão do Departamento de Tecnologia da Informação: “A utilização dos indicadores de desempenho são importantes e fundamentais para o alcance de resultados, como em qualquer outro segmento. A diferença é que no terceiro setor o resultado nem sempre é financeiro.” (informação verbal).

Corroborando o relato, Kaplan (2001) apresenta que a satisfação das entidades do terceiro setor está ligada à satisfação da missão e dos objetivos; destaca, ainda, que resultados financeiros são importantes, mas não primordiais nessas organizações.

\section{CONCLUSÃO}

A utilização de ferramentas de monitoramento, controle e análise de desempenho está cada vez mais evidente e necessária, principalmente ao analisar a situação e o cenário econômico e competitivo em que as organizações estão se deparando. No terceiro setor o cenário não é diferente, ao mesmo passo que as organizações crescem, a competitividade e a necessidade de evolução são latentes. 
Nesse contexto, unindo a necessidade de criar ferramentas de controle e a complexidade do terceiro setor, nesta pesquisa teve-se como objetivo compreender quais indicadores de desempenho são utilizados por entidades do terceiro setor, mais especificamente os sindicatos, e de que forma eles auxiliam na gestão dessas entidades.

Neste trabalho buscou-se identificar a ideia dos gestores em relação à aplicabilidade, ao alinhamento com os objetivos da entidade e à percepção dos indicadores como ferramenta de gestão.

Foi possível evidenciar que a avaliação de desempenho faz parte da cultura organizacional do sindicato, utilizando ferramentas como: planejamento estratégico, participação em programas de qualidade do segmento e indicadores de desempenho.

Todos os departamentos pesquisados utilizam indicadores de desempenho, com medições distribuídas entre semestrais e anuais. As divulgações são realizadas por meio de relatórios e reuniões.

Grande parte dos indicadores utilizados pelos departamentos pesquisados está relacionada às informações não financeiras, quantitativas e qualitativas. A informação financeira está presente na relação de indicadores, contudo, não como fator principal.

Nesta pesquisa conclui-se que a opinião dos entrevistados é uniforme ao considerar a relevância da utilização dos indicadores, assim como a aderência ao conceito de ferramenta de gestão para o terceiro setor.

A principal contribuição do trabalho está na proposta de trazer um entendimento dos indicadores de desempenho utilizados por um sindicato patronal, uma vez que trabalhos dessa natureza não foram localizados, porém, cabe destacar que na pesquisa se apresentam algumas limitações, já que pelo fato de a análise ter sido realizada em apenas uma entidade não é possível assumir que os resultados encontrados sejam os mesmos de outros sindicatos, inclusive de outros segmentos.

Para pesquisas futuras, como sugestão, pode-se ampliar a linha de pesquisa envolvendo novos segmentos ou ainda a expansão da pesquisa entre os sindicatos patronais, possibilitando a comparabilidade das informações obtidas. 


\section{REFERÊNCIAS}

ASSAF NETO, A.; ARAÚJO, A. P; FREGONESI, M. S. F. A. Gestão baseada em valor aplicada ao terceiro setor. Revista Contabilidade e Finanças - USP, p. 105118, 2006. Edição comemorativa.

ÁVILA, L. A. C.; BERTERO, C. O. Governança no terceiro setor: um estudo de caso em uma fundação de apoio universitário. Revista Brasileira de Gestão de Negócios, v. 18, n. 59, p. 124-144, 2016.

BARNEY, J. Firm Resources and Sustained Competitive Advantage. Journal of Management, v. 17, i. 1, p. 99-120, 1991.

BONFIM, E. T.; TEIXEIRA, W. S.; CALLADO, A. L. C. Utilização de Indicadores de Desempenho em Micro e Pequenas Empresas: Um estudo em empresas localizadas em João Pessoa/PB. Desafio Online, v. 1, n. 1, 2013.

BORTOLUZZI, S. C. et al. Avaliação de desempenho econômico-financeiro: Uma proposta de integração de indicadores contábeis tradicionais por meio da metodologia multicritério de apoio à decisão construtivista (MCDA-C). Revista Alcance-Eletrônica, v. 18, n. 2, p. 200-218, 2011.

BRASIL. Consolidação das leis do trabalho. 1943. Disponível em: <http://www. planalto.gov.br/ccivil_03/decreto-lei/del5452compilado.htm>. Acesso em: 15 dez. 2017.

CAIRNS, B. et al. Improving Perfomance? The Adoption and Implementation of Quality Systems in U.K. Nonprofit Management \& Leadership, v. 16, i. 2, p. 135151, 2005.

CALLADO, A. A. C.; CALLADO, A. L. C.; ALMEIDA, M. A. A. A utilização de indicadores de desempenho não financeiros em organizações agroindustriais: um estudo exploratório. Organizações Rurais \& Agroindustriais, Lavras, v. 10, n. 1, p. 35-48, 2008a.

CALLADO, A. A. C.; CALLADO, A. L. C.; ALMEIDA, M. A. A. Determinando padrões de utilização de indicadores de desempenho em organizações agroindustriais. RIC - Revista de Informação Contábil, v. 5, n. 2, p. 82-98, 2011.

CALLADO, A. A. C.; CALLADO, A. L. C.; ALMEIDA, M. A. A. Determinando padrões de utilização de indicadores de desempenho: Um estudo em Micro e Pequenas Empresas da cidade de João Pessoa. Revista UnB Contábil, Brasília, DF, v. 11, n. 1-2, p. 18-29, 2008b. 
Callado, A. A. et al. Relacionando fatores gerenciais com o uso de indicadores de desempenho em empresas do porto digital. Revista de Negócios, Blumenau, v. 17, n. 3, p. 20-35, 2012.

CARLOS, F. A. et al. Uma discussão sobre a criação de indicadores de transparência na gestão pública federal como suporte ao ciclo da política pública. Revista de Contabilidade do Mestrado em Ciências Contábeis da UERJ, v. 13, n. 2, p. 1-15, 2008.

CRUZ, J. A. W. et al. avaliação de Desempenho no Terceiro Setor: uma abordagem teórica de strategic accounts. REBRAE - Revista Brasileira de Estratégia, Curitiba, v. 2, n. 1, p. 11-26, jan./abr. 2009.

DUTRA, A. Metodologia para avaliar o desempenho organizacional: revisão e proposta de uma abordagem multicritério. Revista Contemporânea em Contabilidade, v. 1, n. 3, p. 25-56, 2005.

ENSSLIN, L.; VIANNA, W. B. A. utilização de Ferramentas gerenciais na gestão do terceiro setor: relevância do BSC - uma aplicação. GEPROS - Gestão da Produção, Operações e Sistemas, v. 3, n. 1, p. 61-71, 2007.

ESTENDER, A. C.; FREITAS, L. R.; CARVALHO, A. Balanced Scorecard no processo de integração do terceiro setor. Revista Terceiro Setor \& Gestão, UNG OnLine, v. 1, n. 1, p. 22-28, 2007.

FERREIRA, A.; OTLEY, D. The design and use of performance management systems: an extended framework for analysis. Management Accouting Research, v. 20, i. 4, p. 263-282, 2009.

FIGUEIREDO, M. A. D. et al. Definição de atributos desejáveis para auxiliar a auto-avaliação dos novos sistemas de medição de desempenho organizacional. Gest. Prod., São Carlos, v. 12, n. 2, p. 305-315, ago. 2005.

FISCHMANN, A. A.; ZILBER, M. A. Utilização de Indicadores de Desempenho para a Tomada de Decisões Estratégicas: Um Sistema de Controle. Revista de Administração Mackenzie, ano 1, n. 1, p. 9-25, 2000.

FRARE, E. et al. Indicadores de desempenho em instituições de ciência, tecnologia e inovação: estudo de caso do Laboratório Nacional de Luz Síncrotron. Revista de Administração Pública, v. 48, n. 5, p. 1229-1252, 2014.

GARCIA, F. T. et al. Um estudo sobre indicadores de desempenho na perspectiva do cliente a partir do Balanced Scorecard. Revista de Administração da UNIMEP, São Paulo, v. 11, n. 1, p. 52, 2013. 
GIL, A. C. Como elaborar projetos de pesquisa. 4 ed. São Paulo: Atlas, 2002.

IBGE. Fundações privadas e associações sem fins lucrativos no Brasil. Rio de Janeiro, 2010.

KAPLAN, R. S.; NORTON, D. P. Strategic Performance Measurement and Management in Nonprofit Organizations. Nonprofit Management \& Leadership, v. 11, i. 3, p. 353-370, 2001.

KAPLAN, R. S.; NORTON, D. P. The balanced scorecard - measures that drive performance. Harvard Business Review, Boston, v. 70, p. 71-79, Jan./Feb. 1992.

KLANN, R. C.; BEUREN, I. M. Características que influenciam o disclosure voluntário de indicadores de desempenho. Brasilian Bussiness Review, Vitória, v. 8, i. 2, p. 98-118, 2011.

KUENG, P.; MEIER, A.; WETTSTEIN, T. Computer-based performance measurement in SMEs: Is there any option? Switzerland: University of Fribourg: Institute of Informatics: Internal Working Paper, 2000.

LUGOBONI, L. F. et al. Modelo de Avaliação de desempenho em instituições sem fins lucrativos: proposta de um modelo. In: CONGRESSO NACIONAL DE EXCELÊNCIA EM GESTÃO, 10., 2014, Rio de Janeiro. Anais eletrônicos... Rio de Janeiro, 2014. Disponível em: <http://www.inovarse.org/sites/default/files/ t14_0432_3.pdf>. Acesso em: 15 ago. 2017.

MACEDO, M. A. S.; BARBOSA, A. C. T. A. M.; CAVALCANTE, G. T. Desempenho de agências bancárias no Brasil: aplicando análise envoltória de dados (DEA) a indicadores relacionados às perspectivas do BSC. Revista Economia \& Gestão, Minas Gerais, v. 19, n. 19, 2009.

MARQUES, B. A. et al. Terceiro Setor: panorama das tendências de 1998 a 2013 por meio de um estudo bibliométrico. Enfoque Reflexão Contábil, UEM-PARANÁ, v. 34, n. 2, p. 71-89, 2015.

MARQUEZAN, L. H. F.; DIEHL, C. A.; ALBERTON, J. R. Indicadores não financeiros de avaliação de desempenho: análise de conteúdo em relatórios digitais anuais. Contabilidade, Gestão e Governança, Brasília DF, v. 6, n. 2, p. 46-61, maio/ago. 2013.

MINISTÉRIO DO TRABALHO E EMPREGO. Aferição Central Sindical Analítica. 2013. Disponível em: <http://trabalho.gov.br/sindicatos-consulta-afericao-centrais>. Acesso em: 115 dez. 2017. 
MUNARETTO, L. F.; CORRÊA, H. L. Indicadores de Desempenho Organizacional: Uso e Finalidades nas Cooperativas de Eletrificação do Brasil. Revista Contabilidade Vista e Revista, v. 27, n. 1, jan./abr. 2016.

NASCIMENTO, S. et al. Mapeamento dos indicadores de desempenho organizacional em pesquisas da área de administração, ciências contábeis e turismo no período de 2000 a 2008. R. Adm., São Paulo, v. 46, n. 4, p. 373-391, 2011.

PIZA, S. C. T. et al. A Aderência das Práticas Contábeis do Terceiro Setor às Normas Brasileiras de Contabilidade: Um Estudo Multicaso de Entidades do Município de São Paulo -SP. Revista de Contabilidade do Mestrado em Ciências Contábeis da UERJ, Rio de Janeiro, v. 17, n. 3, p. 78-97, set./dez. 2012.

REZENDE, I. C. C.; DIENG, M.; MORAES JÚNIOR, V. F. Análise comparativa da utilização de indicadores financeiros e não financeiros em hotéis da cidade de João Pessoa - PB: um estudo com enfoque na Gestão Estratégica. Interface - Revista do Centro de Ciências Sociais Aplicadas, v. 8, n. 1, p. 111-127, 2011.

SALAMON, L. A emergência do Terceiro Setor - uma revolução associativa global. Revista de Administração, v. 33, n. 1, p. 5-11, 1998.

SOUZA, A. E.; CORRÊA, H. L. Indicadores de Desempenho em Pequenas e Médias Empresas. RPCA - Revista Pensamento Contemporâneo em Administração, Rio de Janeiro, v. 8, n. 3, p. 118-136, jul./set. 2014.

SOUZA, F. A.; SOUZA, B. C. Análise de Desempenho em ONGs: propondo um modelo adaptado. RESAC - Revista Sociedade, Administração e Contemporaneidade, v. 1, n. 1, p. 21-32, 2011.

VALENTE, S. A. Indicadores de desempenho como ferramenta de alinhamento estratégico - A experiência do Senac Paraná. Revista Ibero-Americana de Estratégia - RIAE, Paraná, v. 13, n. 4, out./dez. 2014.

VIGNOCHI, L.; GONÇALO, C. R.; LEZANA, A. G. R. Como gestores hospitalares utilizam indicadores de desempenho? Revista de Administração de Empresas, v. 54, n. 5, p. 496-509, 2014. 


\section{Como citar este artigo:}

\section{ABNT}

LUGOBONI, Leonardo Fabris et al. Indicadores de desempenho como ferramenta de gestão no terceiro setor: um caso prático aplicado a um sindicato patronal.

RACE, Revista de Administração, Contabilidade e Economia, Joaçaba: Ed. Unoesc, v. 17, n. 2, p. 732-756, maio/ago. 2018. Disponível em: <http://editora.unoesc. edu.br/index.php/race>. Acesso em: dia/mês/ano.

\section{APA}

Lugoboni, L. F., Cabral, C. S. C., Chirotto, A. R., \& Zittei, M. V. M. (2018). Indicadores de desempenho como ferramenta de gestão no terceiro setor: um caso prático aplicado a um sindicato patronal. RACE, Revista de Administração, Contabilidade e Economia, 17(2), 732-756. Recuperado em dia/mês/ano, de http://editora.unoesc. edu.br/index.php/race 
